\title{
PENGARUH KUALITAS PRODUK DAN HARGA TERHADAP PROSES KEPUTUSAN PEMBELIAN KONSUMEN PRODUK AIR MINERAL AQUA \\ Rafiqa Muriska Pandia ${ }^{1)}$, Kadunci') dan Diana D. C. Hutagalung ${ }^{3)}$ \\ Program Studi Administrasi Bisnis Terapan,Politeknik Negeri Jakarta \\ Email: ${ }^{1}$ 11rafiqamp@gmail.com, ${ }^{2}$ dun_c59@yahoo.com, ${ }^{3}$ Hutagalungdiana@yahoo.com
}

\begin{abstract}
This research aims to find out how the influence between product quality and prices of consumer purchasing decisions. Data collection using the questionnaire given to the respondents to obtain primary data and secondary data to obtain an libraries. While the method of data analysis using inferensial statistical analysis, test validity and reliability, test, test the significance of classical assumptions, analysis of the coefficient of determination and multiple regression analysis. Results of the study showed that the quality of the product and the price has a strong influence on the buying decision process. The quality of the product and the price effect of $55.6 \%$ of purchase decisions and the remaining $44.4 \%$ are influenced by other factors such as advertising, brand image factor and others.

Multiple linear regression analysis results obtained persamaan $Y=20.2160,121 X 10,610 X 2$. Of the equation there are constants of 20.216 meaning if the quality of the product and the price is worth 0 then the consumer's decision to purchase the AQUA mineral water of 20.216.The regression coefficient values on the variable quality of products poositif of 0.121 meaning if product quality improved 1 value, then the purchasing decisions of consumers against products of instant noodles rose by 0.121 . The regression coefficient values on the variable price of poositif 0.610 meaning if prices increased the value of 1 , then the purchasing decisions of consumers against products of mineral water AQUA rose by 0.610. If the quality of the product and the price value of the coefficient of increase one means the amount of the purchase decision process increases to 20.947.

The test results on the test $t$ significance obtained product quality variable value indicates the value thitung $=1.412<$ ttabel $=1.662$-value significance of $0.162>0.10$. This means 1 Hypothesis is not accepted. The value for a variable price showed the value of thitung $=$ ttabel $>7.413=1.662$-value significance of $0.0000<0.10$. This means the hypothesis 2 received. The calculation result statistics showed the value of Fhitung $=$ Ftabel $>55.474=2.37$ significance and value of $0.000<0.10$. This means the hypothesis 3 received.
\end{abstract}

Key words: Product Quality, Price, Purchase Decisions Process

\section{Abstrak}

Penelitian ini bertujuan untuk mengetahui seberapa pengaruh antara kualitas produk dan harga terhadap proses keputusan pembelian konsumen. Pengumpulan data menggunakan kuesioner yang diberikan kepada responden untuk memperoleh data primer dan studi kepustakaan untuk memperolah data sekunder. Sedangkan metode analisis data menggunakan analisis statistik inferensial, uji validitas dan reliabilitas, uji asumsi klasik, uji signifikansi, analisis koefisien determinasi dan analisis regresi berganda. Hasil penelitian menunjukan bahwa kualitas produk dan harga memiliki pengaruh yang kuat terhadap proses keputusan pembelian. Kualitas produk dan harga memiliki pengaruh sebesar 55,6\% terhadap proses keputusan pembelian dan sisanya 44,4\% dipengaruhi oleh faktor lain seperti faktor iklan, citra merek dan lain-lainnya.

Hasil analisis regresi linier berganda diperoleh persamaan $Y=20,216+0,121 X 1+0,610 X 2$. Dari persamaan tersebut terdapat nilai konstanta sebesar 20,216 artinya apabila kualitas produk dan harga bernilai 0 maka keputusan konsumen untuk membeli produk air mineral AQUA sebesar 20,216. Nilai koefisien regresi pada variabel kualitas produk poositif sebesar 0,121 artinya jika kualitas produk ditingkatkan 1 nilai, maka keputusan pembelian konsumen terhadap produk Indomie naik sebesar 0,121. Nilai koefisien regresi pada variabel harga poositif sebesar 0,610 artinya jika harga 
ditingkatkan 1 nilai, maka keputusan pembelian konsumen terhadap produk air mineral AQUA naik sebesar 0,610.Jika kualitas produk dan harga nilai koefisiennya meningkat satu artinya jumlah proses keputusan pembelian meningkat menjadi 20,947.

Hasil pengujian pada uji signifikansi t diperoleh nilai variabel kualitas produk menunjukan nilai thitung $=1,412<$ ttabel $=1,662$ dengan nilai signifikansi sebesar 0,162 >0,10. Dengan nilai signifikansi dibawah 0,10 tersebut menunjukan bahwa kualitas produk memiliki tidak mempengaruhi terhadap proses keputusan pembelian. Hal ini berarti Hipotesis 1 tidak diterima. Nilai untuk variabel harga menunjukan nilai thitung = 7,413 > ttabel $=1,662$ dengan nilai signifikansi sebesar 0,0000< 0,10. Hal ini berarti hipotesis 2 diterima. Hasil perhitungan statistik menunjukan nilai Fhitung = 55,474 $>$ Ftabel $=2,37$ dan nilai signifikansi sebesar 0,000 $<0,10$. Hal ini berarti hipotesis 3 diterima.

Kata kunci: Kualitas Produk, Harga, Proses Keputusan Pembelian

\section{PENDAHULUAN}

\section{Latar Belakang}

Air mineral atau biasa disebut air putih sangat penting untuk tubuh manusia, sebab air mineral itu bebas dari kalori dan gula. Meminum air mineral dapat membantu menjaga kesehatan kulit pada tubuh, membantu pencernaan dalam tubuh, membantu mengendalikan asupan kalori tubuh, dan masih banyak lagi lainnya. Dengan mengkonsumsi air mineral setiap hari akan membantu tubuh agar tetap terjaga dan sehat dalam menjalankan aktifitas sehari-hari.

Produk air mineral AQUA memiliki persepsi yang kuat dikalangan masyarakat khususnya di Indonesia. Hal ini dapat dibuktikan pada saat seseorang ingin membeli air mineral di Toko Klontong untuk melepaskan dahaganya, maka seseorang tersebut secara tidak sadar akan bertanya kepada penjual dengan pertanyaan “apa ada AQUA?” atau “ada AQUA?" dan penjual pun akan memberikan produk air mineral yang dijualnya, namun bisa produk yang di jual bermerek AQUA ataupun merek lainnya dan pembeli pun menerima saja untuk membeli walaupun bukan merek AQUA. Hal ini menunjukkan bahwa secara tidak sadar seseorang telah berpersepsi bahwa air mineral itu adalah AQUA, walaupun sebenarnya AQUA itu hanyalah sebuah merek air mineral saja.

Pada tahun 2014 AQUA grup menjadi perusahaan air dalam kemasan pertama di
Indonesia yang mendapatkan anugerah dari Kementrian Lingkungan Hidup dan Kehutanan Republik Indonesia. Adapun anugerah yang diberikan adalah anugerah Program Penilaian Peringkat Kinerja Perusaan (PROPER) Hijau. Kementrian Indonesia ini memberikan PROPER Hijau kepada empat perusahaan AQUA grup atas implementasi sistem produk bersih dan program pemberdayaan masyarakat yang telah melebihi standard yang sudah ditetapkan. Keempat pabrik itu antara lain Pabrik AQUA Mekarsari, Pabrik AQUA Mambal, Pabrik AQUA Pandaan, dan Pabrik AQUA Airmadidi. (www.AQUA.com:2017)

Adapun hasil dari Top Brand Award 2012 sampai dengan 2016 pada produk Air Minum Dalam Kemasan yang digunakan oleh para konsumen di Indonesia antara lain sebagai berikut:

Tabel 1. Top Brand Award Air Minum dalam Kemasan 2012 - 2016

\begin{tabular}{|c|c|c|c|c|c|c|}
\hline \multirow[t]{2}{*}{ No. } & \multirow[t]{2}{*}{ Merek } & \multicolumn{5}{|c|}{ Tahun } \\
\hline & & 2012 & 2013 & 2014 & 2015 & 2016 \\
\hline 1 & AQUA & $81.0 \%$ & $81.6 \%$ & $75.2 \%$ & $75.9 \%$ & $73.4 \%$ \\
\hline 2 & Club & $3.2 \%$ & $3.7 \%$ & $3.4 \%$ & $5.0 \%$ & $3.4 \%$ \\
\hline 3 & Ades & $2.6 \%$ & $2.3 \%$ & $2.2 \%$ & $2.6 \%$ & $3.4 \%$ \\
\hline 4 & VIT & $2.1 \%$ & $3.1 \%$ & $3.2 \%$ & $2.6 \%$ & $5.5 \%$ \\
\hline 5 & Viro & $1.4 \%$ & $1.0 \%$ & $1.4 \%$ & - & - \\
\hline 6 & RON 88 & $1.2 \%$ & - & $1.4 \%$ & - & - \\
\hline 7 & Amidis & $1.1 \%$ & - & - & - & - \\
\hline 8 & SanQua & - & - & $1.4 \%$ & - & - \\
\hline 9 & Cleo & - & - & - & - & $2.0 \%$ \\
\hline 10 & 2Tang & - & - & - & - & $1.4 \%$ \\
\hline
\end{tabular}

Pada tabel ini menunjukan bahwa banyak pesaing air minum dalam kemasan khususnya kategori air mineral dari berbagai macam merek. Hal ini membuat 
konsumen pun semakin mempertimbangkan kembali bagaimana mencari keputusan pembelian air mineral yang baik. Saat ini dapat dilihat pada mahasiswa Administrasi Niaga di Politeknik Negeri Jakarta, beberapa mahasiswa sering mengkonsumsi air mineral AQUA. Banyak faktor yang mempengaruhi mahasiswa Administrasi Niaga memutuskan untuk membeli air mineral tersebut.

Dari latar belakang yang dibuat oleh penulis, maka penulis akan membahas lebih lanjut mengenai harga dalam suatu produk dalam pengambilan keputusan. Untuk itu penulis mengangkat judul penelitian "Pengaruh Kualitas Produk Dan Harga Terhadap Proses Keputusan Pembelian Konsumen Produk Air Mineral AQUA"

\section{Tujuan}

Adapun tujuan penelitian yang ingin dicapai penulis adalah untuk menganalisis seberapa besar pengaruh kualitas produk dan harga terhadap proses keputusan pembelian.

\section{Permasalahan}

Rumusan masalah yang timbul yaitu "Pengaruh Kualitas Produk dan Harga Terhadap Proses KeputusanPembelian”.

\section{Kajian Pustaka}

Penelitian ini didasarkan pada beberapa teori sebagai berikut.

\section{Pengertian Pemasaran}

Menurut Sudaryono (2016:42) menjelaskan bahwa pemasaran merupakan suatu perpanduan dari aktifitas-aktifitas yang saling berhubungan untuk mengetahui kebutuhan konsumen melalui penciptaan, penawaran, dan pertukaran produk dan jasa yang bernilai serta mengembangkan promosi, distribusi, pelayanan, dan harga agar kebutuhan konsumen dapat terpuaskan dengan baik pada tingkat keuntungan tertentu.
Sedangkan Meldurm dalam Sudaryono (2016:41) mengatakan bahwa Pemasaran (marketing) didefinisikan sebagai:

"Pemasaran adalah proses bisnis yang berusaha menyelaraskan antara sumber daya manusia, financial dan fisik organisasi dengan kebutuhan dan keinginan para pelanggan dalam konteks strategi kompetitif.”

\section{Pengertian Kualitas Produk}

Produk memiliki arti penting bagi perusahaan karena tanpa adanya produk, perusahaan tidak akan dapat melakukan apapun dari usahanya. Pembeli akan membeli produk kalau merasa cocok, karena itu produk harus disesuaikan dengan keinginan ataupun kebutuhan pembeli agar pemasaran produk berhasil dan tujuan perusahaan tercapai.

Menurut Kotler dan Armstrong (2008:272) pengertian kualitas produk adalah:

"Kualitas produk adalah karakteristik produk atau jasa yang bergantung pada kemampuannya untuk memuaskan kebutuhan pelanggan yang dinyatakan atau diimplikasikan”.

Sedangkan Davis (1994) dalam Yamit (2013:8) berpendapat bahwa kualitas produk adalah:

"Kualitas merupakan suatu kondisi dinamis yang berhubungan dengan produk, jasa, manusia, proses dan lingkungan yang memenuhi atau melebihi harapan”.

Perusahaan yang menghasilkan produk lebih menekankan pada hasil, karena konsumen umumnya tidak terlibat secara langsung dalam prosesnya. Untuk itu diperlukan sistem manajemen kualitas yang dapat memberikan jaminan kepada pihak konsumen bahwa produk tersebut dihasilkan oleh proses yang berkualitas.

\section{Pengertian Harga}

Harga memainkan peran strategik dalam pemasaran. Penetapan harga merupakan hal yang harus dipertimbangkan oleh suatu perusahaan. 
Banyak faktor yang harus dipertimbangkan oleh suatu perusahaan guna mendapatkan harga yang sesuai dengan produk dan menguntungkan untuk perusahaan.

Menurut Kotler dan Armstrong (2008:63) pengertian dari harga sebagai berikut:

"Harga adalah jumlah uang yang harus dibayarkan pelanggan untuk memperoleh produk.”

Sedangkan Supranto dan Limakrisna (2007:12) berpendapat bahwa harga sebagai berikut:

"Harga adalah sejumlah uang seseorang harus membayar untuk mendapatkan hak menggunakan produk.”

Fadil dan Utama (2015:139) menyatakan pendapat bahwa harga sebagai berikut:

"Harga adalah besaran yang dibayar oleh konsumen untuk mendapatkan produk atau jasa yang dijual oleh bisnis anda."

Menurut Tjiptono (2015:298) secara garis besar metode penetapan harga dapat dikelompokkan menjadi empat kategori utama, yaitu metode penetapan harga berbasis permintaan, berbasis biaya, berbasis laba, dan berbasis persaingan.

Dari difinisi diatas dapat disimpulkan bahwa harga merupakan sejumlah uang yang dikeluarkan oleh konsumen untuk mendapatkan atau memeliki produk atau jasa yang diinginkan.

\section{Pengertian Proses Keputusan Pembelian}

Menurut Supranto (2005:1)

pengambilan keputusan sebagai berikut:

"Secara populer dapat dikatakan bahwa pengambilan atau membuat keputusan berarti memilih satu dari diantara sekian banyak alternatif."

Kotler dan Armstrong (2008:181) menyatakan bahwa keputusan pembelian konsumen sebagai berikut:

"Keputusan pembelian (purchase decision) konsumen adalah membeli merek yang paling disukai, tetapi dua faktor yang berbeda antara niat pembelian dan keputusan pembelian.”
Pengambil kepututusan ataupun memutuskan berarti memilih salah satu pilihan dari dua pilihan atau lebih. Konsumen melakukan pengambilan keputusan dikarenakan untuk mencari apa yang sedang konsumen cari untuk suatu hal yang ingin dicapai.

Kotler dan Armstrong (2008:179-181) berpendapat bahwa proses keputusan pembeli adalah sebagai berikut:

\section{Pengenalan kebutuhan}

Proses pembelian dimulai dengan pengenalan kebutuhan (need recognition) pembeli menyadari suatu masalah atau kebutuhan. Kebutuhan dapat dipicu oleh rangsangan internal ketika salah satu kebutuhan normal seseorang seperti rasa lapar, haus timbul pada tingkat yang cukup tinggi sehingga menjadi dorongan. Kebutuhan juga bisa dipicu oleh rangsangan eksternal seperti iklan. Pada tahap ini pemasar harus meneliti konsumen untuk menemukan jenis kebutuhan atau masalah apa yang timbul, apa yang menyebabkannya, dan bagaimana masalah itu bisa mengarahkan konsumen pada produk tertentu.

\section{Pencarian informasi}

Konsumen yang tertarik mungkin mencari lebih banyak informasi atau mungkin tidak. Pencarian informasi adalah tahap proses keputusan pembeli dimana konsumen ingin mencari informasi lebih banyak, konsumen mungkin hanya memperbesar perhatian atau melakukan pencarian informasi secara aktif. Konsumen dapat memperoleh informasi dari beberapa sumber. Sumber-sumber ini meliputi sumber pribadi (keluarga, teman, tetangga, rekan), sumber komersial (iklan, wiraniaga, situs web, penyalur, kemasan, tampilan), sumber publik (media massa, organisasi pemeringkat konsumen, pencarian internet), dan sumber pengalaman (penanganan, pemeriksaan, pemakaian produk). Pengaruh relatif sumber-sumber informasi ini bervariasi sesuai produk dan pembelinya. 


\section{Evaluasi alternative}

Evaluasi elternatif adalah tahap proses keputusan pembeli dimana konsumen menggunakan informasi untuk mengevaluasi merek alternatif dalam sekelompok pilihan. Pemasar harus mempelajari pembeli untuk menemukan bagaimana cara mereka sebenarnya dalam mengevaluasi pilihan merek. Jika mereka tahu proses evaluasi apa yang berlangsung, pemasar dapat mengambil langkah untuk mempengaruhi keputusan pembeli.

\section{Keputusan pembelian}

Dalam tahap evaluasi, konsumen menentukan peringkat merek dan membentuk niat pembelian. Pada umunya, keputusan pembelian (purchase decision) konsumen adalah membeli merek yang paling disukai, tetapi dua faktor bisa berada antara niat pembelian dan keputusan pembelian. Faktor pertama adalah sikap orang lain. Faktor kedua adalah faktor situasional yang tidak diharapkan. Konsumen mungkin membentuk niat pembelian berdasarkan faktor-faktor seperti pendapatan, harga, dan manfaat produk yang diharapkan.

\section{Perilaku pasca pembelian}

Setelah membeli produk, konsumen akan merasa puas atau tidak puas dan terlibat dalam perilaku pasca pembelian (postpurchase behavior) yang harus diperhatikan oleh pemasar. Perilaku pasca pembelian adalah tahap proses keputusan pembeli dimana konsumen mengambil tindakan selanjutnya setelah pembelian, berdasarkan kepuasan atau ketidak puasan mereka. Faktor yang menentukan tingkat kepuasan konsumen adalah ekspektasi konsumen dan kinerja anggapan produk. Jika produk tidak memenuhi ekspektasi, konsumen kecewa, jika produk memenuhi ekspektasi, konsumen puas, jika produk melebihi ekspektasi konsumen sangat puas. Semakin besar kesenjangan antara ekspektsi dan kinerja, semakin besar pula ketidakpuasan konsumen. Hal ini menunjukan bahwa penjual hanya boleh menjanjikan apa yang dapat diberikan mereknya sehingga pembeli terpuaskan.

\section{METODE PENELITIAN Metode Penelitian}

Variabel - variabel yang akan diteliti dalam penelitian ini adalah kualitas produk $\left(\mathrm{X}_{1}\right)$, harga $\left(\mathrm{X}_{2}\right)$ sebagai variabel bebas dan proses keputusan pembelian sebagai variabel terikat (Y).

\section{Populasi dan Sampel}

Penelitian ini perlu menentukan responden yang akan menjadi sumber informasi dengan cara menentukan populasi dan sampel yang akan digunakan.

\section{Populasi}

Populasi yang akan digunakan pada penelitian ini adalah mahasiswa Administrasi Niaga, di Politeknik Negeri Jakarta dengan jumlah 757 mahasiswa.

\section{Sampel}

Penelitian ini menentukan sampel dengan menggunakan rumus slovin.

$$
\mathrm{n}=\frac{757}{(757) 0.1^{2}+1}=\frac{757}{8.57}=88,33=\mathbf{8 8}
$$

\section{Teknis Analisis Data}

Analisis yang digunakan pada penelitian ini adalah analisis kuantitatif yang merupakan metode analisis dengan angka-angka yang dapat dihitung maupun diukur.

\section{Uji Instrumen}

Uji instrumen dilakukan pada angket yang diberikan kepada responden.

\section{Uji Validitas}

Uji validitas adalah tingkat keandalan dan kesahihan alat ukur yang digunakan. Menggunakan rumus Product Moment.

\section{Uji Reliabilitas}

Uji relibiltas dilakukan dengan tujuan untuk mengetahui apakah instrument yang digunakan dapat mengukur tanpa 
kesalahan dan dapattetap konsisten atau sama dalam mengukur suatu variable. Untuk menganalisis reliabilitas instrument penelitian, penulis menggunakan software SPSS ver 23.

\section{Uji Normalitas}

Uji normalitas pada penelitian ini adalah dengan menggunakan test Kolmogorov-Smirnov dalam Sugiyono (2012: 326) dengan menggunakan aplikasi SPSS versi 23.

\section{Uji Multikolinieritas}

Uji ini dilakukan untuk analisis regresi berganda yang terdiri atas dua atau variabel bebas, di mana akan diukur tingkat keeratan pengaruh antar variabel bebas tersebut melalui besaran oefisien korelasi (r).

\section{Uji Heterokedastisitas}

Uji ini dilakukan untuk untuk menguji apakah dalam model regresi terjadi ketidaksamaan varian residual antara yang satu dengan yang lain. Jika varians residual dari suatu pengamatan ke pengamatan yang lain tetap maka disebut homokedastisitas.

\section{Uji Hipotesis}

Uji hipotesis yang digunakan dalam penelitian ini terdiri dari analisis regresi linier berganda, analisis koefisien determinasi $\left(\mathrm{R}^{2}\right)$, Uji Signifikansi (uji $\mathrm{T}$ ) dan uji simultan (uji statistik F).

\section{HASIL DAN PEMBAHASAN}

Bab hasil penelitian dan pembahasan ini berisi penjelasan mengenai data dan pembahasan temuan penelitian.

\section{Uji Validitas Instrumen}

Tabel 2. Variabel Kualitas Produk $\left(X_{1}\right)$

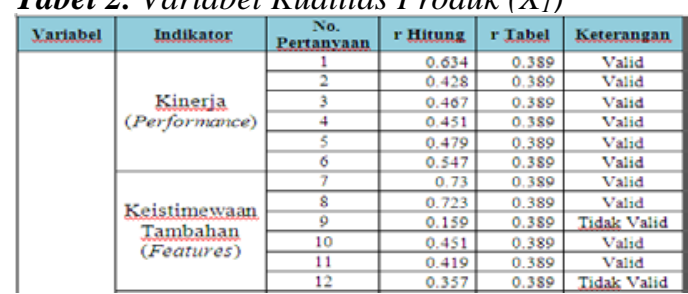

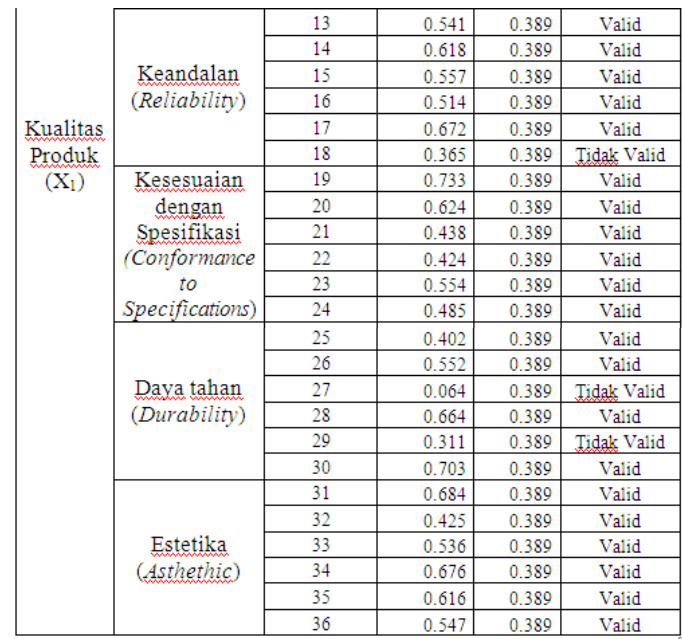

Tabel 3. Variabel Harga $\left(X_{2}\right)$

\begin{tabular}{|c|c|c|c|c|c|}
\hline Variabel & Indikator & $\begin{array}{c}\text { No. } \\
\text { Pertanyaan }\end{array}$ & $r$ Hitung & r Tabel & Keterangan \\
\hline \multirow{35}{*}{$\frac{\text { Harga }}{\left(\mathrm{X}_{2}\right)}$} & \multirow{8}{*}{$\begin{array}{c}\text { Keterjangkau } \\
\text { an Harga }\end{array}$} & 37 & 0.485 & 0.389 & Valid \\
\hline & & 38 & 0.667 & 0.389 & Valid \\
\hline & & 39 & 0.624 & 0.389 & Valid \\
\hline & & 40 & 0.781 & 0.389 & Valid \\
\hline & & 41 & 0.298 & 0.389 & Tidak Valid \\
\hline & & 42 & 0.547 & 0.389 & Valid \\
\hline & & 43 & 0.447 & 0.389 & Valid \\
\hline & & 44 & 0.628 & 0.389 & Valid \\
\hline & \multirow{7}{*}{$\begin{array}{c}\text { Kesesuaian } \\
\text { Harga } \\
\text { Dengan } \\
\text { Kualitas } \\
\text { Produk }\end{array}$} & 45 & 0.122 & 0.389 & Tidak Valid \\
\hline & & 46 & 0.337 & 0.389 & Tidak Valid \\
\hline & & 47 & 0.414 & 0.389 & Valid \\
\hline & & 48 & 0.188 & 0.389 & Tidak Valid \\
\hline & & 49 & 0.653 & 0.389 & Valid \\
\hline & & 50 & 0.676 & 0.389 & Valid \\
\hline & & 51 & 0.511 & 0.389 & Valid \\
\hline & \multirow{7}{*}{$\begin{array}{c}\text { Daya Saing } \\
\text { Harga }\end{array}$} & 52 & 0.183 & 0.389 & Tidak Valid \\
\hline & & 53 & 0.423 & 0.389 & Valid \\
\hline & & 54 & 0.431 & 0.389 & Valid \\
\hline & & 55 & 0.618 & 0.389 & Valid \\
\hline & & 56 & 0.425 & 0.389 & Valid \\
\hline & & 57 & 0.442 & 0.389 & Valid \\
\hline & & 58 & 0.402 & 0.389 & Valid \\
\hline & \multirow{7}{*}{$\begin{array}{c}\text { Harga } \\
\text { Mempengaru } \\
\text { hi Daya Beli } \\
\text { Konsumen }\end{array}$} & 59 & 0.657 & 0.389 & Valid \\
\hline & & 60 & 0.502 & 0.389 & Valid \\
\hline & & 61 & 0.573 & 0.389 & Valid \\
\hline & & 62 & 0.600 & 0.389 & Valid \\
\hline & & 63 & 0.122 & 0.389 & Tidak Valid \\
\hline & & 64 & 0.646 & 0.389 & Valid \\
\hline & & $\begin{array}{l}65 \\
66\end{array}$ & $\begin{array}{l}0.147 \\
0.837\end{array}$ & $\begin{array}{l}0.389 \\
0.389\end{array}$ & $\begin{array}{c}\text { Tidak Valid } \\
\text { Valid }\end{array}$ \\
\hline & \multirow{6}{*}{$\begin{array}{c}\text { Harga dapat } \\
\text { Mempengaru } \\
\text { hi Konsumen } \\
\text { dalam } \\
\text { Mengambil } \\
\text { Keputusan }\end{array}$} & 67 & 0.670 & 0.389 & Valid \\
\hline & & 68 & 0.414 & 0.389 & Valid \\
\hline & & 69 & 0.610 & 0.389 & Valid \\
\hline & & 70 & 0.724 & 0.389 & Valid \\
\hline & & 71 & 0.627 & 0.389 & Valid \\
\hline & & 72 & 0.407 & 0.389 & Valid \\
\hline
\end{tabular}

Tabel 4. Variabel Proses Keputusan Pembelian (Y)

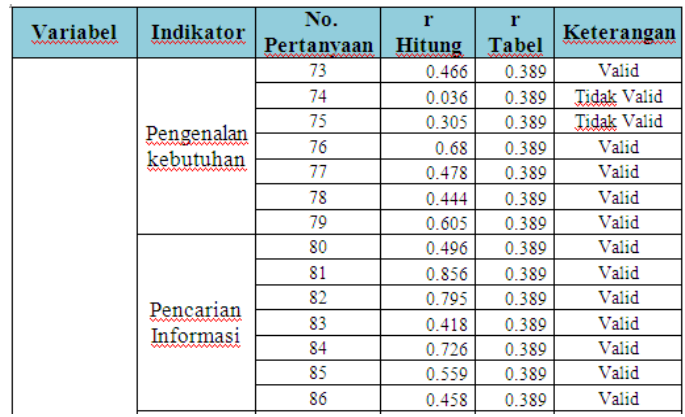




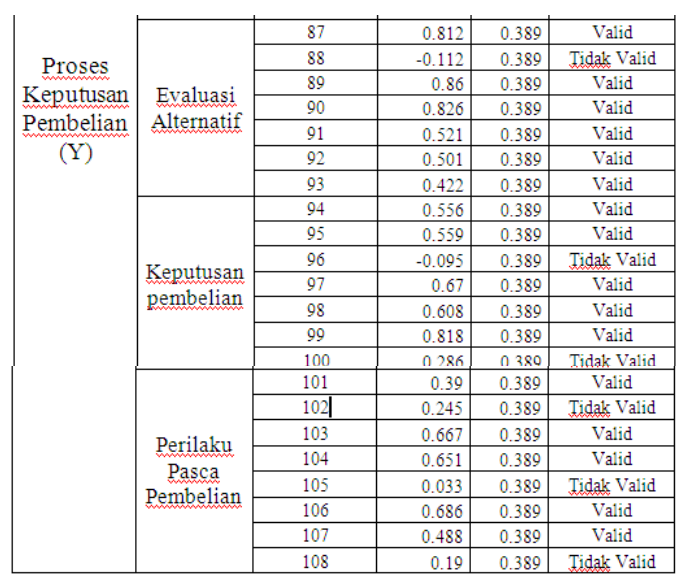

\section{Karakteristik Responden}

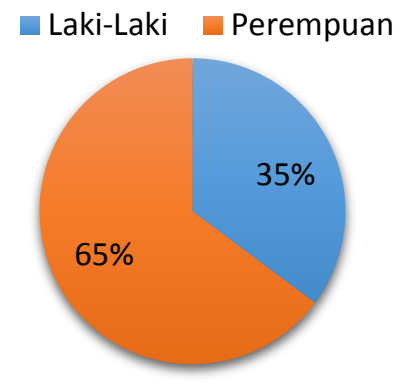

Gambar 1. Grafik Responden Berdasarkan Jenis Kelamin (Sumber: Data Diolah, 2017)

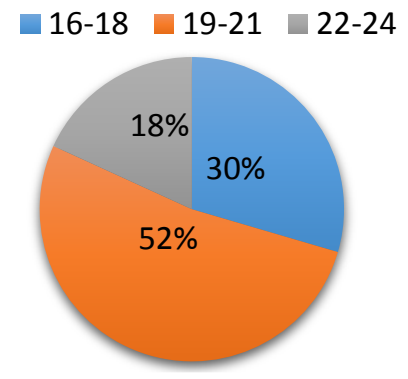

Gambar 2. Grafik Responden Berdasarkan Rentang Usia (Sumber: Data Diolah, 2017)

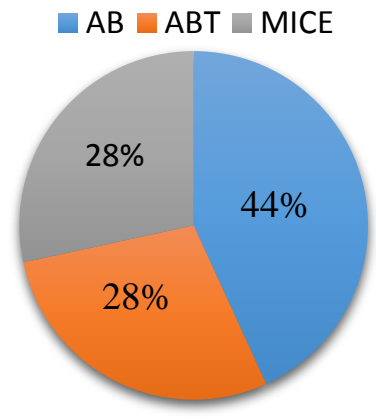

Gambar 3. Grafik Responden BerdasarkanProgram Studi (Sumber: Data Diolah, 2017)

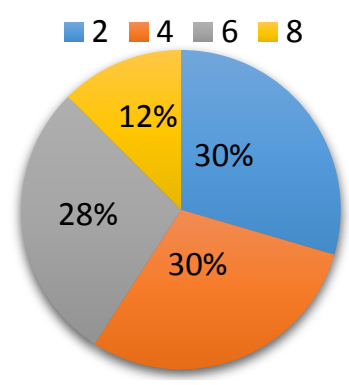

Gambar 4. Grafik Responden Berdasarkan Jenjang Semester (Sumber: Data Diolah, 2017)

\section{Uji Normalitas}

Hasil normalitas sebagai berikut:

Tabel 5. Hasil Uji Normalitas (KolmogorovSmirnov)

\begin{tabular}{llr}
\hline & & $\begin{array}{c}\text { Unstandardize } \\
\text { d Residual }\end{array}$ \\
\hline $\mathrm{N}$ & Mean & 88 \\
Normal & 5.1917637 \\
Parameters & Std. Deviation & 1.89691645 \\
Most Extreme & Absolute & .072 \\
Differences & Positive & .072 \\
& Negative & -.051 \\
Test Statistic & & .072 \\
Asymp. Sig. (2-tailed) & $.200^{\mathrm{c}, \mathrm{d}}$ \\
\hline Sumber: Data Diolah, 2017 &
\end{tabular}

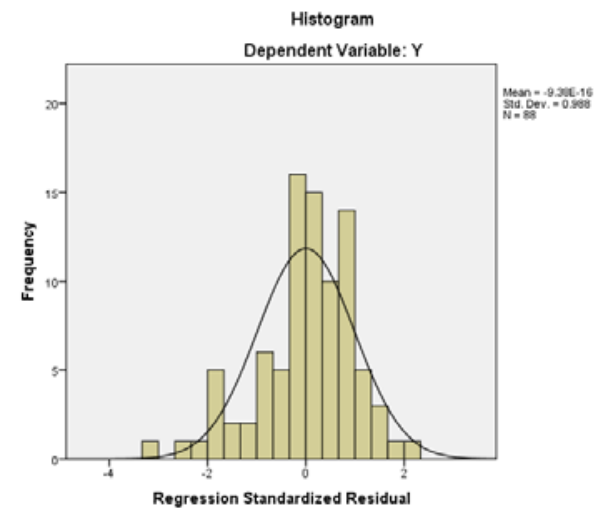

Gambar 5. Grafik Histogram (Sumber: Data Diolah, 2017)

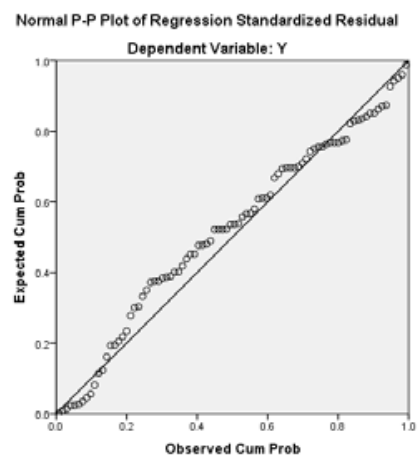

Gambar 6. Grafik P-P Plot of Regression (Sumber: Data Diolah, 2017) 
Uji Multikolinieritas

Tabel 6. Hasil Uji Multikolinieritas

\begin{tabular}{lrr}
\hline \multirow{2}{*}{ Model } & \multicolumn{2}{c}{ Collinearity Statistics } \\
\cline { 2 - 3 } & Tolerance & \multicolumn{1}{c}{ VIF } \\
\hline 1 (Constant) & .628 & 1.592 \\
Kualitas Produk & .628 & 1.592 \\
Harga &
\end{tabular}

*Dependent Variable: Proses Keputusan

Pembelian

Sumber: Data Diolah, 2017

\section{Uji Heterokedastisitas}

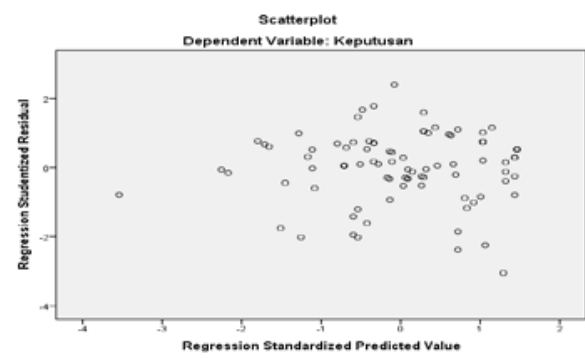

Gambar 6. Hasil Analisi Uji Heterokedastisitas (Sumber: Data Diolah, 2017)

\section{Analisis Regresi Linier Berganda}

Tabel 7. Hasil Analisi Regresi Linier Berganda

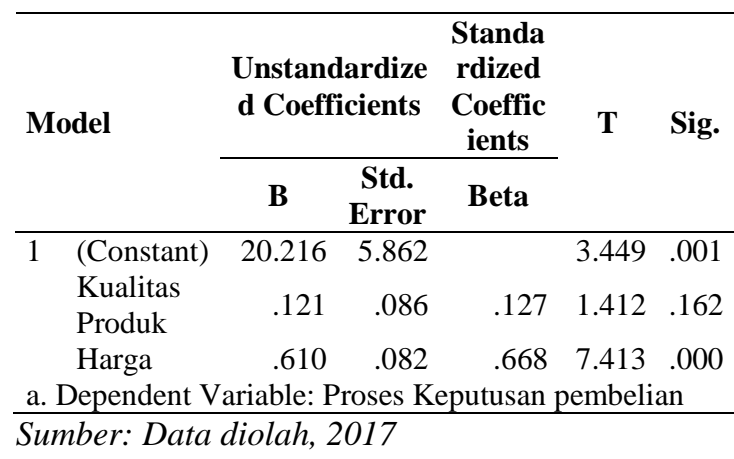

\section{Analisis Koefisien Determinasi $\left(\mathbf{R}^{\mathbf{2}}\right)$}

Tabel 8. Koefisien Determinasi

\begin{tabular}{ccrrr} 
Model & \multirow{2}{*}{$\begin{array}{c}\text { R } \\
\text { Square }\end{array}$} & $\begin{array}{r}\text { Adjusted } \\
\text { R Square }\end{array}$ & $\begin{array}{r}\text { Std. Error of } \\
\text { the Estimate }\end{array}$ \\
\hline 1 & $.752^{\mathrm{a}}$ & .566 & .556 & 3.77234
\end{tabular}

a. Predictors: (Constant), Kualitas Produk, Harga

b. Dependent Variable: Keputusan

Sumber: Data Diolah, 2017
Uji Signifikansi (Uji T)

Tabel 9. Hasil Analisi Signifikasi T

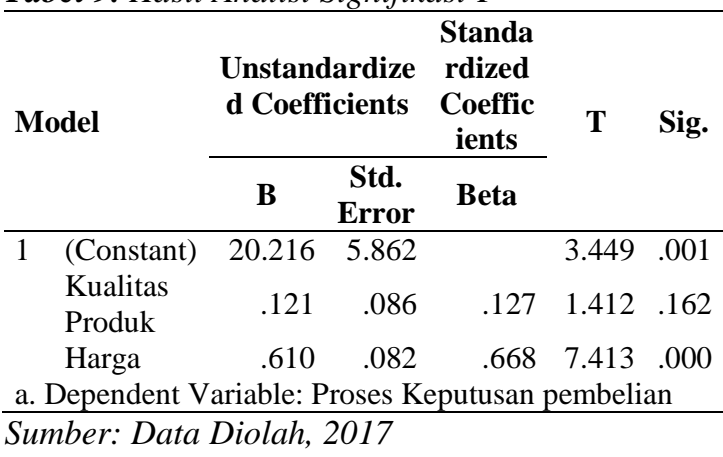

Uji Simultan (Uji Statistik F)

Tabel 10. Hasil Analisi Signifikasi F

\begin{tabular}{|c|c|c|c|c|c|c|}
\hline \multicolumn{7}{|c|}{ ANOVA $^{a}$} \\
\hline & del & $\begin{array}{l}\text { Sum of } \\
\text { Squares }\end{array}$ & Df & $\begin{array}{c}\text { Mean } \\
\text { Square }\end{array}$ & F & Sig. \\
\hline \multirow[t]{3}{*}{$\frac{1}{1}$} & Regression & 1578.847 & 2 & 789.423 & 55.47 & .00 \\
\hline & Residual & 1209.596 & 85 & 14.231 & & \\
\hline & Total & 2788.443 & 87 & & & \\
\hline
\end{tabular}

a. Dependent Variable: Proses Keputusan

Pembelian

Sumber: Data Diolah, 2017

\section{KESIMPULAN}

Hasil pengujian pada uji signifikansi t diperoleh nilai variabel kualitas produk menunjukan nilai thitung $=1,412<$ ttabel $=$ 1,662 dengan nilai signifikansi sebesar $0,162>0,10$. Dengan nilai signifikansi lebih dari 0,10 tersebut menunjukan bahwa kualitas produk memiliki tidak mempengaruhi terhadap keputusan pembelian. Hal ini berarti Hipotesis 1 tidak terbukti. Pada bagian ini menunjukkan bahwa konsumen di Politeknik Negeri Jakarta Jurusan Administrasi Niaga tidak mementingkan kualitas produk air mineral AQUA.

Hasil pengujian pada uji signifikansi $t$ diperoleh nilai variabel harga menunjukan nilai thitung $=7,413>$ ttabel $=1,662$ dengan nilai signifikansi sebesar $0,0000<$ 0,10. Dengan nilai signifikansi di bawah 0,10 tersebut menunjukan bahwa harga memiliki pengaruh terhadap keputusan pembelian. Hal ini berarti hipotesis 2 terbukti. Pada bagian ini menunjukkan bahwa konsumen di Politeknik Negeri 
Jakarta Jurusan Administrasi Niaga lebih mementingkan harga dalam menentukan pembelian produk air mineral AQUA.

Hasil perhitungan statistik menunjukan nilai Fhitung $=55,474>$ Ftabel $=2,37$ dan nilai signifikansi sebesar $0,000<0,10$. Dengan nilai signifikansi dibawah 0,10 menunjukan bahwa secara simultan kualitas produk dan harga mempunyai pengaruh terhadap proses keputusan pembelian konsumen produk air mineral AQUA pada konsumen Administrasi Niaga di Politeknik Negeri Jakarta.

\section{DAFTAR PUSTAKA}

Fadil, Zaki dan Utama, Priyo. 2015. Teknik Marketing Itu Mudah. Yogyakarta: Second Hope

Kotler, Philip dan Armstrong, Gary. 2008. Prinsip-Prinsip Pemasaran. Jakarta: Erlangga.

Kotler, Philip.,dan Kevin Lane Keller. 2007. Manajemen Pemasaran. Edisi Kedua Belas. Jilid 2. Jakarta: PT. Indeks.

Kotler, Philip.,dan Kevin Lane Keller. 2008. Manajemen Pemasaran. Edisi Tigas Belas. Jilid 1. Jakarta: PT. Indeks.

Kotler, Philip.,dan Kevin Lane Keller. 2008. Manajemen Pemasaran. Edisi Tiga Belas. Jilid 2. Jakarta: PT. Indeks.

Kotler, Philip dan Keller, Kevin Lane. 2009. Manajemen Pemasaran. Jakarta: Erlangga.

Noor, Juliansyah. 2011. Metodologi Penelitian. Jakarta: Kencana Prenada Group.

Mowen, John C dan Minor, Michael. 2002. Prilaku Konsumen. Jakarta: Erlangga.

Nitisusastro, Mulyadi. 2012. Prilaku Konsumen. Bandung: Alfabeta.

Sanusi, Anwar. 2011. Metodologi
Penelitian Bisnis. Jakarta: Salemba Empat.

Sudaryono. 2016. Manajemen Pemasaran Teori dan Implementasi. Yogyakarta: Andi.

Sugiyono. 2010. Metode Penelitian Kuantitatif, Kualitatif, dan R\&D. Bandung: Alfabeta

Sugiyono. 2016. Metode Penelitian Kuantitatif, Kualitatif, dan R\&D. Bandung: Alfabeta.

Supranto, J dan Limakrisna, Nandan. 2007. Prilaku Konsumen dan Strategi Pemasaran. Jakarta: Mitra Kencana Media.

Supranto, J. 2005. Teknik Pengambilan Keputusan. Jakarta: Rineka Cipta.

Tjiptono, Fandy. 2015. Srategi Pemasaran Edisi Empat. Yogyakarta: Andi.

Tjiptono, Fandy dan Diana Anastasia. 2016. Pemasaran. Yogyakarta: Andi.

Yamit, Zulian. 2013. Manajemen Kualitas Produk dan Jasa. Yogyakarta: Ekonisia.

Website:

www.aqua.com:2017

www.topbrand-award.com 
Rafiqa M.P, Kadunci dan Diana D.C.H Pengaruh Kualitas Produk.. 